NOTAS

\title{
FLAITE: ALGUNOS APUNTES ETIMOLÓGICOS
}

$193-200$

Dario Rojas*

\section{INTRODUCCIÓN}

La palabra flaite, "persona de clase social baja y comportamiento extravagante, que es relacionada generalmente con el mundo delictual", según la definición del Diccionario de uso del español de Chile, quizá sea uno de los más recurrentes objetos de atención para los aficionados a buscar el origen de ciertas expresiones lingüísticas que caracterizan al español de Chile. Las etimologías populares para este término son variadas y dan cuenta de diversas facetas de los estereotipos sociales vinculados con sus referentes. Creemos que es, precisamente, su significado, que alude a personas de cierta condición social, lo que motiva que los chilenos hayamos prestado tanta atención a esta palabra: sabido es que en nuestro país somos muy sensibles a las diferencias entre grupos socioeconómicos. En consecuencia, los hablantes del español de Chile hemos intentado racionalizar su existencia mediante el "hallazgo", más bien invención, de su origen. Racionalizar, decimos, porque mediante un proceso ideológico afín al conocido como iconización (Irvine y Gal, 2000), los chilenos creemos haber encontrado motivaciones causales entre el origen lingüístico de la palabra flaite y ciertas conductas o rasgos considerados propios de las personas a quienes esta refiere, transformando a estas últimas en estereotipos sociales.

Con la presente nota nos proponemos hacer un pequeño aporte al esclarecimiento del origen de este término desde el punto de vista de las ciencias del lenguaje. Para este último propósito nos apoyaremos en los procedimientos de la etimología, esto es, en términos simples, la disciplina lingüístico-histórica que investiga el origen de las palabras (Durkin, 2009) o, en términos más especializados, la disciplina que establece y describe los procesos históricos que resultan en nuevas secuencias de fonemas con un significado asociado (Krisch, 2010). Específicamente, procederemos a mostrar que flaite es un anglicismo procedente del español peruano y generalizado en Chile mediante el coa. Para ello tendremos en cuenta las distintas variantes de la palabra que existen en el ámbito hispánico actual y examinaremos las transiciones semánticas del vocablo estudiado, las que permiten fundamentar nuestra propuesta. La hipótesis que defendemos, en síntesis, difiere de las etimologías populares que revisaremos, pero aún debe ser considerada como una primera aproximación al problema, pues hará falta en el futuro emprender el análisis histórico de corpus para corroborarla definitivamente. 


\section{ALGUNAS ETIMOLOGÍAS POPULARES ACERCA DE FLAITE}

No nos referimos aquí a la etimología popular como el tipo de cambio lingüístico debido a asociaciones hechas por los hablantes entre distintos ítems léxicos, que explicaría, por ejemplo, el cambio de la consonante inicial en lat. uerruculum $>$ cast. cerrojo debido a la asociación con cerrar. Más bien la entendemos como la tendencia de los hablantes no especialistas a racionalizar la existencia de un determinado vocablo, construyendo una historia para su origen. En este sentido, el estudio de las etimologías populares formaría parte de la lingüística popular (Niedzielski y Preston, 2003), que se ocupa de investigar los modelos culturales que del lenguaje tienen los no especialistas. Siguiendo a García Manga (2010), también podría darse el nombre de etimologización a esta construcción de racionalizaciones lingüístico-históricas, cuya investigación cuidadosa podría contribuir a responder la pregunta de cómo operan la innovación y el cambio lingüístico de acuerdo con los no especialistas, lo que forma parte del cuerpo de conocimientos que se propone conseguir la lingüística popular.

Una primera opinión, bastante difundida entre los no especialistas, atribuye el origen del vocablo flaite al nombre de un modelo de zapatillas, que habría sido característico de las personas a las que primero se refirió el vocablo. Un artículo del periódico electrónico El Definido lo explica del siguiente modo:

Una de las teorías más fuertes [sobre su origen], señala que la palabra flaite vendría de un modelo de zapatillas llamado Air Flight desarrollado por la marca Nike. Como eran altamente demandadas por los jóvenes y debido a su alto valor, fueron falsificadas. Los modelos piratas se llamaban Flight Airs, de ahí derivó en "flaiters" y su uso se expandió para referirse a los jóvenes que las usaban, normalmente de bajos recursos (El Definido, Conoce el origen de algunos de nuestros chilenismos, 17 de septiembre de 2013)

En un reportaje de un periódico santiaguino (que señala basarse en la opinión de Jaime Campusano), la misma teoría aparece explicada con referencia a un personaje en concreto:

El basquetbolista Michael Jordan, que fue todo un símbolo de los 90, sería el responsable de la palabra "flaite". Su marca de zapatillas, modificó su modelo Flight, a finales de la década noventera, a un diseño auspiciado por el basquetbolista de la NBA. Colores fuertes y plataformas más elevadas, convirtieron a la zapatilla en un deleite de muchos jóvenes chilenos. De flight a "flaite" solo hubo un paso, literalmente (Las Últimas Noticias, 27 de junio de 2012, p. 4).

Es admisible destacar que en todos estos casos el origen del término sería relativamente reciente. El escritor Marco Antonio de la Parra, en un seminario relativo a los flaites organizado por una universidad chilena, señaló, en cuanto a la 
fecha de origen de este término, que, a pesar de las diversas teorías, todo apuntaría a la década de 1990.

Otra teoría dice que flaite viene del inglés flight, o más específicamente de un supuesto sustantivo inglés flighter. En un periódico santiaguino dirigido a público popular se explica así su origen:

Ahora todo el mundo cree que "ser flaite" siempre significó ser vulgar u ordinario o que "un flaite" era un joven marginal de malas costumbres. Pero no, originalmente "flaite" viene de "flight", y les decían así a los "volados" medio "torrejas". De ahí la palabra fue tomando una connotación "picante" ( $\mathrm{La}$ Cuarta, La Ficha Pop, 11 de junio de 2004).

La razón, entonces, sería que primero con esta palabra se hizo referencia a sujetos que andaban "volados", es decir, bajo el efecto de drogas alucinógenas, posiblemente marihuana, y de alguna manera el término se desplazó semánticamente hasta designar delincuentes y también ciertas personas de clase social baja.

También con el hecho de volar, pero en un sentido más literal, vincula otra teoría el origen de la palabra flaite. Esta vez se trataría del inglés fly, referido a los viajes en avión. Se hace partidaria de esta etimología, entre otros, nada menos que la enciclopedia Wikipedia, en su versión en español, aunque también entremezclándola con la teoría que aludía al uso de drogas:

El término flaite pareciera derivarse del inglés flighter (volador), término que se usaba en el lunfardo argentino y uruguayo para denominar a un tipo de ladrón relacionado a los vuelos entre Buenos Aires y Europa. Desde este origen, la palabra migra al español chileno con diferentes usos. En un principio, para designar a los consumidores de marihuana que en Chile son también denominados volados (por el inglés fly), y luego como un adjetivo despectivo utilizado para referirse a ciertas personas de baja condición social, al prejuzgar relacionando la adicción a las drogas con marginalidad (http://es.wikipedia.org/wiki/Flaite).

Las explicaciones hasta ahora señaladas son las que se encuentran con mayor frecuencia hoy en el discurso de los no especialistas. Creemos que estas explicaciones no son plausibles, principalmente porque ubican el momento de génesis de este término en una fecha muy reciente, siendo que los datos de que disponemos (que mostraremos en la siguiente sección) apuntan a una antigüedad mayor. Además, carecen de cualquier respaldo empírico, como ha quedado claro: se trata de elucubraciones muy imaginativas, algunas, pero que no cuentan con datos que las sustenten.

\section{FLAITE $(<$ FAITE) COMO ANGLICISMO PROCEDENTE DEL ESPAÑOL PERUANO}

Primero, corresponde hacer una descripción del uso actual de flaite en Chile. De acuerdo con la Academia Chilena de la Lengua (2010), este término tiene varios 


\section{Dario Rojas}

significados: 1) "persona de clase social baja y comportamiento extravagante, que es relacionada generalmente con el mundo delictual"; 2) como adjetivo, "relativo a los flaites [en la primera acepción]"; 3) también como adjetivo, "que tiene características negativas típicamente asociadas a los flaites [en la acepción 1], como mala educación, mal gusto, mala calidad o relación con la delincuencia, entre otras"; y, por último, 4) como adjetivo referido a una persona, "de clase social baja". La Asociación de Academias de la Lengua Española (2009), por su parte, caracteriza sus significados de la siguiente manera: 1) "persona de clase social baja que suele mostrar un comportamiento agresivo y viste de forma un tanto extravagante"; 2) referido a una persona, "de comportamiento poco refinado"; 3) "ladrón"; 4) referido a cosa, "de mal gusto"; y 5) referido también a una cosa, "de mala o poca calidad". Ninguno de estos dos repertorios indica el origen de la voz.

El diccionario de Morales Pettorino (2006), en cambio, propone un origen de manera indirecta. Considera flaite como variante de la voz del coa faite, y para esta última señala origen inglés: fighter, "guerrero", "luchador". Morales Pettorino consigna además que faite "es voz encomiástica", dentro del coa, se entiende, y que significa "delincuente avezado que suele actuar con mucha seguridad y sin temor alguno". Las documentaciones de uso de Morales Pettorino para faite provienen de 1968, 1970 y 1975.

Según nuestra opinión, el origen de flaite es el que se deduce de la información entregada por Morales Pettorino: fighter. La primera pista nos viene del Diccionario de Americanismos, que registra la forma faite para Perú, con los siguientes significados: 1) "matón, pendenciero"; 2) referido a persona, "valiente, atrevida"; 3) referido a persona, "que viste con elegancia y esmero". El origen consignado para este vocablo es el inglés fighter, "luchador". En el Perú, la palabra faite tenía las siguientes connotaciones:

Esta expresión — cuyo uso continúa hasta hoy— designaba, a comienzos del siglo XX, a individuos que llevaban una vida al margen de la ley, mostraban una particular destreza para la pelea, especialmente con arma blanca, se reclamaban valientes y "guapos", y adherían a ciertos códigos de conducta respeto a la palabra empeñada, defensa del honor, cierta caballerosidad en sus actos - que los hacían respetables no solo en el mundo criminal sino también a los ojos de ciertos sectores de la población 'decente' y las autoridades judiciales y policiales. Los faites vivían y reinaban en el submundo de la prostitución, el alcohol, y el juego, y con frecuencia trabajaban para la policía como soplones y torturadores (Aguirre, 12).

De acuerdo con una descripción más sucinta del compositor y escritor peruano Abelardo Gamarra, el faite era "el guapetón que se la da de no tenerle miedo ni al diablo; o el guapo que en verdad no le tiene; el faite es como un jefe o caudillo sobreentendido: el que se impone a pulso" (citado en Aguirre, 12). Borras (2007) señala que el faite venía a ocupar en la urbe el nicho que en lo rural ocupaba el 
bandido. Según Mejía, “con el correr de los años, la figura del faite se degeneró convirtiéndose en delincuente, abusivo y alquilando sus puños al mejor postor" (18).

Hildebrandt señala, respecto del faite limeño:

Este pintoresco tipo de perdonavidas criollo apareció en Lima después de la guerra contra Chile. [...] La palabra faite viene del inglés fighter "luchador, camorrista". Faite es un anglicismo del Perú que pertenece a la etapa (fines del siglo XIX y principios del XX) de influencia del inglés británico (193-194).

Además de la forma faite, en la época se usaba la forma faiteman (Borras, 166; Hildebrandt, 194; Mejía, 18), probablemente de fighter + man, lo que corrobora su origen en la lengua inglesa.

¿Tiene alguna relación la forma faite con nuestro flaite? El parecido formal es más que evidente. Pero el dato decisivo es que existe un registro lexicológico que da cuenta de la existencia de faite en la jerga delincuencial chilena: el coa, desde hace ya varias décadas y con anterioridad a los primeros registros lexicográficos de flaite. De esta manera, se puede pensar en una cronología relativa faite $>$ flaite. Benavides (1966), al comenzar la segunda mitad del siglo XX, registra faite "delincuente", faite funao "delincuente conocido por la policía" y faite piola "delincuente nuevo", así como la expresión faite canilla "ladrón barato" entre los vocablos "recopilados mediante consultas a funcionarios de Investigaciones, Prisiones y Reos", lo que da cuenta de que debe haber tenido uso real por esos años entre los delincuentes chilenos, y no se trata solo de trasvasije bibliográfico. Poco más de una década después, Méndez Carrasco (1979) consigna faite "ladrón, en general" y chorifaite "fusión de choro (delincuente habitual) con faite". Ni faite ni flaite se encuentran registrados en Vicuña (1910), el primer repertorio lexicográfico conocido de coa, de manera que habrá que pensar que su difusión en el español de Chile habrá sido posterior a ese año. Flaite es registrado también en diccionarios de coa, pero de época más reciente. Candia (1998), por ejemplo, lo recoge definido como "delincuente respetado, que viste elegantemente y tiene trato caballeroso". Ello da cuenta de que el significado original de faite pudo haberse mantenido, parcialmente al menos, en el ámbito delincuencial.

El cambio fónico que lleva de faite a flaite implicaría solo la inserción de una /1/ epentética con el resultado de la formación de un grupo consonántico, fenómeno de variación no desconocido para el español vernáculo chileno. Gormaz (1860), Ortúzar (1893) y Echeverría y Reyes (1900) registran ejemplos como rampa >rampla y otros que dan cuenta de que, aunque quizá poco frecuente, es una posibilidad de variación fónica, emparentada con la epéntesis de $/ \mathrm{r} /$ en el mismo contexto (pestillo $>$ prestillo, buñuelo $>$ bruñuelo, Calisto $>$ Calistro, etc.), documentada por los autores antes señalados y otros.

Expuestos los datos anteriores, podemos pensar que, con mucha probabilidad, nuestro flaite se remonta al faite peruano de comienzos del siglo XX, y que, por tanto, el origen último de flaite es el inglés fighter "peleador", como señalaba Morales 


\section{Dario Rojas}

Pettorino (2006). La vía de ingreso del término desde Perú pudo haber sido portuaria (vehículo frecuente de difusión lingüística), o cualquier otra, en realidad (tampoco podríamos descartar por ahora un surgimiento paralelo). Además de la similitud formal (fónica) y la plausibilidad del cambio $f a$ - $>f l a$-, existe en varias asociaciones semánticas que permiten apreciar una relación entre ambos términos. El rasgo semántico fundamental de faite dice relación con la conducta agresiva de un personaje de los barrios bajos, lo que explica, en primer lugar, su origen en un derivado del verbo que en la lengua de origen alude a una conducta agresiva (pelear). Luego, en el español de Chile, las primeras documentaciones inscriben a este personaje dentro del ámbito de la delincuencia. Dentro de este ámbito, la violencia física se presenta como recurso para hacerse respetar entre los pares. Nótese que la definición de flaite de Candia (1998) dice que se trata no de cualquier delincuente, sino que de un delincuente respetado, que probablemente ocupa una posición jerárquica alta entre sus colegas. Piénsese, como punto de comparación, en el caso de choro. Este vocablo, que tiene origen en el caló jergal (Salillas, 1896), significa en Chile "ladrón que tiene mucho prestigio entre sus pares y que se caracteriza fundamentalmente por su actuar violento", y también, referido a persona,"que suele adoptar una actitud desafiante y confrontacional, frecuentemente asociada con violencia física" (Diccionario de uso del español de Chile). El faitelflaite, entonces, de modo análogo al choro, debió en un comienzo haber sido el delincuente que, por saber manejar a su conveniencia la violencia, era respetado. Al emanar su semanticidad desde el punto de vista interno al grupo que maneja la denominación, era un término cargado de connotaciones positivas (recuérdese el carácter "encomiástico" de la voz, según indica Morales Pettorino). Luego, al extenderse su uso fuera del ámbito delictual (quizá en los años 90, como señalaba Marco Antonio de la Parra, y de acuerdo con lo que Candia (1998) señala respecto del momento de generalización de palabras que antiguamente eran privativas del coa), esta connotación debió haber cambiado a signo negativo, debido a la percepción social negativa de la delincuencia existente en la sociedad, digamos, "normal". Esto explicaría la carga despectiva que tiene hoy en Chile el uso de flaite, según el Diccionario de uso del español de Chile y el Diccionario de Americanismos, además de los significados secundarios que focalizan rasgos estereotípicos percibidos por la sociedad en las personas a que se refiere el término: condición social baja, mala educación, mal gusto, mala calidad, etcétera, todos de cariz negativo.

\section{4. ¿CONCLUSIÓN?}

No pretendemos haber concluido la pesquisa etimológica relativa a flaite. La hipótesis que defendemos (a saber, que flaite viene de faite, usado primero en el coa chileno, que lo tomó a su vez del español peruano de comienzos del siglo $\mathrm{XX}$, donde tenía la variante faiteman y fue tomado del inglés fighter o fighter man) quizá podrá contarse entre las demás que hemos criticado al comienzo de este 
trabajo, por su decidido carácter (aún) especulativo. Sin embargo, creemos que esta propuesta, a diferencia de las revisadas al comienzo, tiene al menos algo de sustento en datos $\mathrm{y}$, por tanto, se aproxima más a un proceder etimológico científico. No debe soslayarse, en cualquier caso, el valor que las etimologías que hemos descartado tienen para los estudios de los discursos metalingüísticos populares. Pero esto será tema de otro trabajo.

Como hemos señalado al comienzo, una tarea urgente de acometer, como continuación del presente estudio, es el rastreo textual que permitirá documentar con mayor precisión la historia de faite y los términos relacionados que hemos examinado. En segundo lugar, convendría explorar las posibles situaciones de contacto lingüístico que hayan llevado a la adopción de peruanismos léxicos en el léxico chileno, específicamente en ciertas variedades subestándares como el coa, durante la primera mitad del siglo XX. Sabido es que el léxico chileno ha tomado bastante prestado del español rioplatense, y específicamente del lunfardo (Salamanca, 2010; San Martín, 2011), pero los préstamos del español peruano, hasta donde sabemos, no han sido estudiados. Con un estudio de este tipo podrá corroborarse si faite entró a Chile desde el Perú o si se trata más bien de un anglicismo que llegó paralelamente a diversos lugares del Cono Sur.

$$
\begin{array}{r}
\text { Universidad de Chile* } \\
\text { Facultad de Filosofia y Humanidades } \\
\text { Departamento de Lingüistica } \\
\text { Av. Capitán Ignacio Carrera Pinto 1025, Ñuñoa, Santiago (Chile) } \\
\text { darioroj@u.uchile.cl }
\end{array}
$$

\section{OBRAS CITADAS}

Academia Chilena de la Lengua. Diccionario de uso del español de Chile (DUECh). Santiago: MN Editorial, 2010.

Aguirre, Carlos. "Duelo de caballeros: Lima a comienzos del siglo XX". Libros y Artes: Revista de Cultura de la Biblioteca Nacional 9, 2005:12-15.

Asociación de Academias de la Lengua Española. Diccionario de americanismos. Madrid: Santillana, 2009.

Benavides, Inés. El lenguaje de los delincuentes chilenos (Coa) en la crónica policial. Memoria de Prueba para optar al título de Periodista. Escuela de Periodismo, Universidad de Concepción, 1966.

Borras, Gérard. "Meurtriers, faites et bandoleros: lorsque le vals péruvien chantait la transgression et la norme". Caravelle 88, 2007:157-176.

Candia, Ricardo. Diccionario del coa. Santiago: Latingrafica, 1998.

Durkin, Philip. The Oxford Guide to Etymology. Oxford: Oxford University Press, 2009. 
Echeverría y Reyes, Aníbal. Voces usadas en Chile. Santiago: Imprenta Elzeviriana, 1900.

García Manga, $\mathrm{M}^{\mathrm{a}}$ del Carmen. La etimología popular como fenómeno peculiar de motivación del lenguaje. Tesis doctoral. Cádiz: Servicio de Publicaciones de la Universidad de Cádiz, 2010.

Gormaz, Valentín. Correcciones lexigráficas sobre la lengua castellana en Chile. Valparaíso: Imprenta de El Progreso, 1860.

Hildebrandt, Martha. Peruanismos. Lima: Biblioteca Nacional del Perú, 1994.

Irvine, Judith y Susan Gal. "Language ideology and linguistic differentiation". Regimes of language: Ideologies, polities, and identities. Ed. Paul V. Kroskrity. Santa Fe: School of American Research Press, 2000: 35-84.

Krisch, Thomas. "Etymology". The Continuum Companion to Historical Linguistics. Eds. Silvia Luraghi y Vit Bubenik. London/New York, 2010: 311-322.

Mejía, Darío. "Duelo Criollo". Perú News Review 6, Junio 2007: 18.

Méndez Carrasco, Armando. Diccionario coa. Santiago: Editorial Nascimento, 1979. Morales, Pettorino. Nuevo diccionario ejemplificado de chilenismos y otros usos diferenciales del español de Chile [tomos VI, VII y VIII del Diccionario ejemplificado de chilenismos]. Valparaíso: Puntángeles, 2006.

Niedzielsky, Nancy y Preston, Dennis R. Folk Linguistics. Berlin/New York: Mouton de Gruyter, 2003.

Ortúzar, Camilo. Diccionario manual de locuciones viciosas y de correcciones del lenguaje con indicación del valor de algunas palabras y ciertas nociones gramaticales. San Benigno Canavese: Imprenta Salesiana, 1893.

Salamanca, Gastón. "Apuntes sociolingüísticos sobre la presencia de argentinismos en el léxico del español de Chile". Atenea 502, 2010:125-149.

Salillas, Rafael. El delincuente español: el lenguaje. Estudio filológico, psicológico y sociológico, con dos vocabularies jergales. Madrid: Librería de Victoriano Suárez, 1896.

San Martín, Abelardo. "Voces de origen lunfardo en el registro festivo del diario chileno La Cuarta". Onomázein 23, 2011: 105-147.

Vicuña, Julio. Coa: jerga de los delincuentes chilenos. Estudio y vocabulario. Santiago: Imprenta Universitaria, 1910. 